\title{
Anaesthesia of the Long Buccal Nerve
}

\author{
Lemya Babiker Sanhori* and Elneel Ahmed Mohmed \\ University of Medical Sciences and Technology, Sudan
}

Submission: February 18, 2017; Published: June 29, 2017

*Corresponding author: Lemya Babiker Sanhori, University of Medical Sciences and Technology, Sudan, Tel: +249914727644;

Email: limyasanhori@gmail.com

\begin{abstract}
Background: Painless dental procedure was the main goal behind inventing different methods of local anaesthesia. The block techniques of local anaesthesia have shown some difficulties in application and prolong time to produce an effect. Hence the role of infiltration anaesthesia is also important.
\end{abstract}

Objective: The aim of this study was to identify the best area to anaesthetize the long buccal nerve in intra-alveolar extraction of posterior teeth.

Study design: Controlled experimental hospital based study.

Patients and methods: Two hundred fifty seven patients was selected randomly all the patients were between $20-40$ years, presented for extraction of the lower posterior teeth at KTDH during the period 2008-2011.Patients were categorized into three groups, the first had given block anaesethesia for the long buccal nerve, the second had given infiltration anaesthesia in between the roots of the tooth to be extracted and the third had given infiltration anaesthesia mesial to the tooth to be extracted.Then anaesthesia was tested and the time was measured.

Results: The onset of anaesthesia was faster in the second group as $64.70 \%$ of the patients were anaestized in $0-30$ seconds in comparison to $19.10 \%$ and $16.20 \%$ in the first and third groups respectively.

Conclusion: In extraction of lower posterior teeth the injection of local anaesthesia in between the roots gives more rapid onset of anaesthesia for the long buccal nerve.

Keywords: Anaesthesia; Long buccal nerve; Block anaesthesia; Infiltration Anaesthesia

\section{Introduction}

The use of local anaesthesia in most of the branches of dentistry makes it necessary to bring more effort to develop the means by which it becomes more potent and easier to apply.

Dental practice and especially the minor surgical ones usually done to alleviate pain but also it is vital to have a painless procedure for that.The use of local anaesthesia is preferable over general anaesthesiaas there are many difficulties associated with the use of general anaesthesia [1].

Block anaesthesia of the long buccal nerve still shows some failure with various techniques at the buccal mucosa, gingival, and cortical bone of the mandibular posterior teeth when compared with infiltration anesthesia [2-4].

Looking for factors responsible for failure and slow onset of anesthesia of the long buccal nerve in the mandibular posterior teeth that makes the infiltration technique superior to the block technique; It might be found that some logical explanations are there:
A. Anatomical factors. Like extra innervation from the mylohyoid nerve, abnormal anatomy of the area, or sensory fibers from the cutaneous coli [2-10].

B. Inadequate concentration of anesthetic agent [4].

C. Small amount of anesthetic solution as in some block techniques, it is not safe to give large amount to avoid pressure complications [2].

D. In case of inflammation, the presence of acidic environment increases the action potential that is transmitted along the sensory nerve $[1,3,4]$.

E. Difficulty in delivering anesthetic solution in the right place in some blocking techniques [2].

This research is mainly to determine the best site of anesthesia of the long buccal nerve by infiltration type for the mandibular molars in patients attending Khartoum Teaching Dental Hospital (KTDH). 


\section{Methods}

The study was conducted at Khartoum Teaching Dental Hospital for patients coming for extraction of the lower posterior teeth during (2008-2011). The study design was controlled experimental hospital based study.

The study size was257 patient. Inclusion Criteria as following: age between 20-40. Male and female patients coming for intraalveolar extraction of mandibular second and third molar.

Extraction of first molar, presence of infection and Transalveolar extraction were excluded. Data collection sheet, questionnaire, mirror, probe, syringe, tweezer, disposable needles 27 gauge and $1.8 \mathrm{ml}$ cartridge of $2 \%$ lidocaine and stop watch were used to collect the data.

\section{Study Method}

After selection of patients, patients will be seated in the dental chair and categorized randomly into three groups. History and examination will be done. Then the consent will be filled by the patient. The three groups will be injected with $0.6 \mathrm{ml}$ of lidocaine to anaesthetize the long buccal nerve. The first group will be injected distal and buccal to the last molar in the oral cavity with the needle parallel to the lower occlusal plane.The second one will be injected in between the roots of the tooth to be extracted with the needle 45 degree at the sulcus. The third one will be injected mesial to the tooth to be extracted with the needle 45 degree at the sulcus. Each patients will be tested objectively and subjectively for the onset of anaesthesia at times 0-30, 31-60, 61-90,91-120 and more than 120 secs respectively. Data sheet will be completed. Then the results will be analysed and compared. Stata version 8 was used for data analysis. Verbal and written consent taken from the patient. Written consent taken from KTDH.

Results
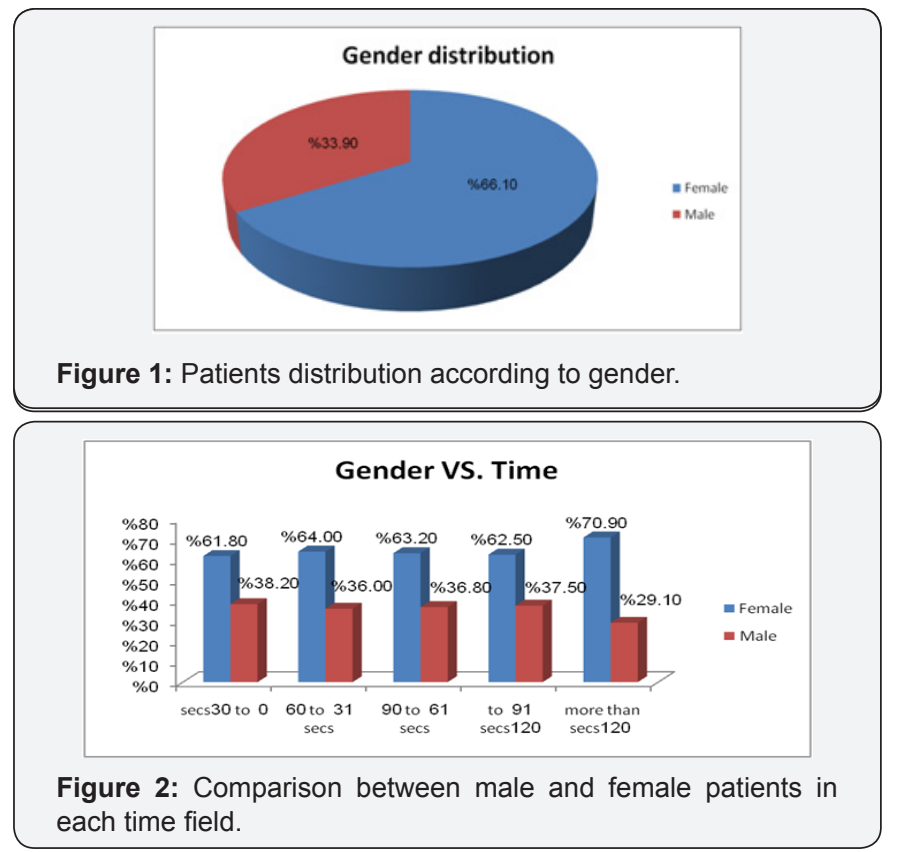

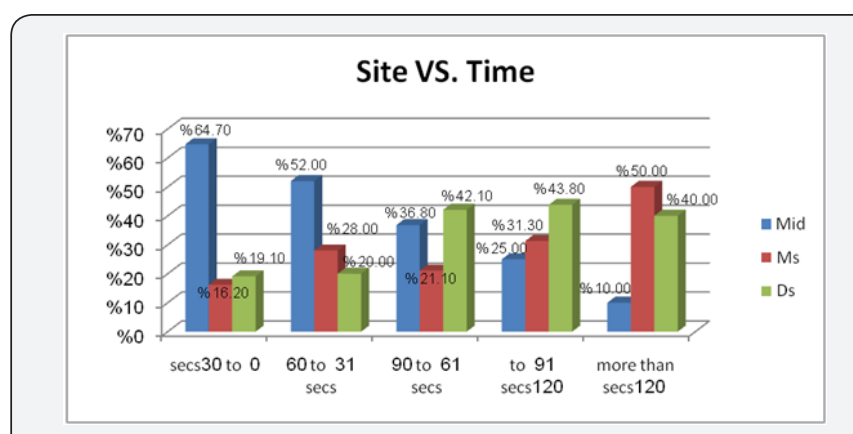

Figure 3: Comparison between the sites of anaesthesia against time. (mid: Middle; Ms: Mesial; Ds: Distal).

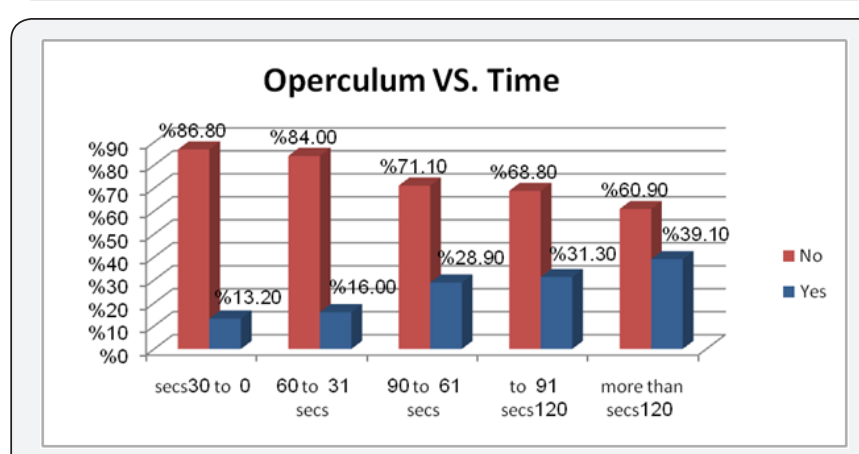

Figure 4: The relation between the on set of anaesthesia in teeth with operculum against teeth without operculum.

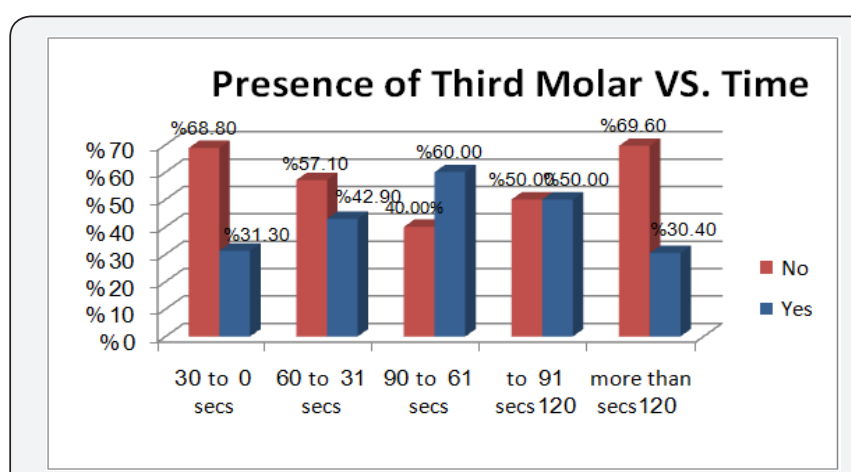

Figure 5: The relation between the on set of anaesthesia in teeth with operculum against teeth without operculum.

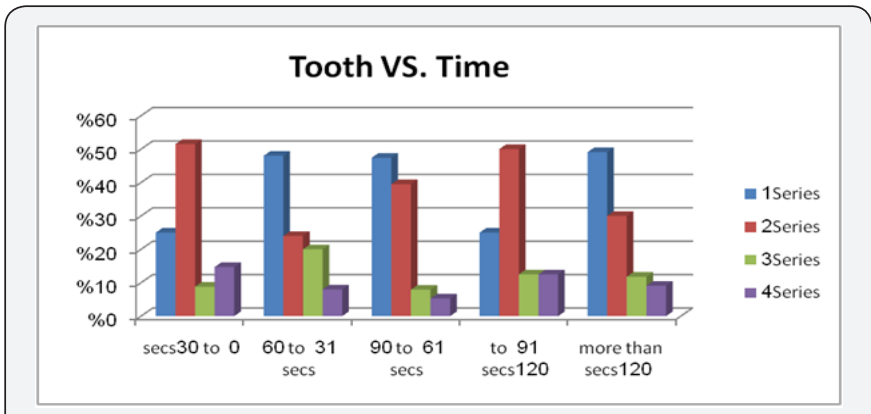

Figure 6: The relation between the on set of anaesthesia in teeth with operculum against teeth without operculum.

Figure 1-6, Table 1-5. 
Table 1: Descriptive analysis of the study.

\begin{tabular}{|c|c|c|c|c|c|c|c|c|c|c|c|c|}
\hline \multicolumn{13}{|c|}{ Time } \\
\hline & \multicolumn{2}{|c|}{0 to 30 secs } & \multicolumn{2}{|c|}{31 to 60 secs } & \multicolumn{2}{|c|}{61 to $90 \mathrm{sec}$} & \multicolumn{2}{|c|}{91 to $120 \mathrm{sec}$} & \multicolumn{2}{|c|}{ More than 120 secs } & \multicolumn{2}{|c|}{ Total } \\
\hline & Frequency & Percent & Frequency & Percent & Frequency & Percent & Frequency & Percent & Frequency & Percent & Frequency & Percent \\
\hline \multicolumn{13}{|c|}{ Gender } \\
\hline Female & 42 & $61.80 \%$ & 16 & $64.00 \%$ & 24 & $63.20 \%$ & 10 & $62.50 \%$ & 78 & $70.90 \%$ & 170 & $66.10 \%$ \\
\hline Male & 26 & $38.20 \%$ & 9 & $36.00 \%$ & 14 & $36.80 \%$ & 6 & $37.50 \%$ & 32 & $29.10 \%$ & 87 & $33.90 \%$ \\
\hline Total & 68 & $100.00 \%$ & 25 & $100.00 \%$ & 38 & $100.00 \%$ & 16 & $100.00 \%$ & 110 & $100.00 \%$ & 257 & $100.00 \%$ \\
\hline \multicolumn{13}{|c|}{ Site } \\
\hline Mid & 44 & $64.70 \%$ & 13 & $52.00 \%$ & 14 & $36.80 \%$ & 4 & $25.00 \%$ & 11 & $10.00 \%$ & 86 & $33.50 \%$ \\
\hline Ms & 11 & $16.20 \%$ & 7 & $28.00 \%$ & 8 & $21.10 \%$ & 5 & $31.30 \%$ & 55 & $50.00 \%$ & 86 & $33.50 \%$ \\
\hline Ds & 13 & $19.10 \%$ & 5 & $20.00 \%$ & 16 & $42.10 \%$ & 7 & $43.80 \%$ & 44 & $40.00 \%$ & 85 & $33.10 \%$ \\
\hline Total & 68 & $100.00 \%$ & 25 & $100.00 \%$ & 38 & $100.00 \%$ & 16 & $100.00 \%$ & 110 & $100.00 \%$ & 257 & $100.00 \%$ \\
\hline \multicolumn{13}{|c|}{ Operculun } \\
\hline No & 59 & $86.80 \%$ & 21 & $84.00 \%$ & 27 & $71.10 \%$ & 11 & $68.80 \%$ & 67 & $60.90 \%$ & 185 & $72.00 \%$ \\
\hline Yes & 9 & $13.20 \%$ & 4 & $16.00 \%$ & 11 & $28.90 \%$ & 5 & $31.30 \%$ & 43 & $39.10 \%$ & 72 & $28.00 \%$ \\
\hline Total & 68 & $100.00 \%$ & 25 & $100.00 \%$ & 38 & $100.00 \%$ & 16 & $100.00 \%$ & 110 & $100.00 \%$ & 257 & 100.005 \\
\hline \multicolumn{13}{|c|}{ Eight } \\
\hline No & 11 & $68.80 \%$ & 4 & $57.10 \%$ & 2 & $40.00 \%$ & 2 & $50.00 \%$ & 16 & $69.60 \%$ & 35 & $63.60 \%$ \\
\hline Yes & 5 & $31.30 \%$ & 3 & $42.90 \%$ & 3 & $60.00 \%$ & 2 & $50.00 \%$ & 7 & $30.40 \%$ & 20 & $36.40 \%$ \\
\hline Total & 16 & $100.00 \%$ & 7 & $100.00 \%$ & 5 & $100.00 \%$ & 4 & $100.00 \%$ & 23 & $100.00 \%$ & 55 & $100.00 \%$ \\
\hline \multicolumn{13}{|l|}{ Tooth } \\
\hline Right 8 & 17 & $25.00 \%$ & 12 & $48.00 \%$ & 18 & $47.40 \%$ & 4 & $25.00 \%$ & 54 & $49.40 \%$ & 105 & $40.90 \%$ \\
\hline Left 8 & 35 & $51.50 \%$ & 6 & $24.00 \%$ & 15 & $39.50 \%$ & 8 & $50.00 \%$ & 33 & $30 . .00 \%$ & 97 & $37.70 \%$ \\
\hline Right 7 & 6 & $8.80 \%$ & 5 & $20.00 \%$ & 3 & $7.90 \%$ & 2 & $12.50 \%$ & 13 & $11.80 \%$ & 29 & $11.30 \%$ \\
\hline Left 7 & 10 & $14.71 \%$ & 2 & $8.00 \%$ & 2 & $5.30 \%$ & 2 & $12.50 \%$ & 10 & $9.10 \%$ & 26 & $10.10 \%$ \\
\hline Total & 68 & $100.00 \%$ & 25 & $100.00 \%$ & 38 & $100.00 \%$ & 16 & $100.00 \%$ & 110 & $100.00 \%$ & 257 & $100.00 \%$ \\
\hline
\end{tabular}

Table 2: Percentage of gender distribution.

\begin{tabular}{|c|c|c|}
\hline Gender & Frequency & Percent \\
\hline Female & 170 & $66.10 \%$ \\
\hline Male & 87 & $33.90 \%$ \\
\hline Total & 257 & $100.00 \%$ \\
\hline
\end{tabular}

Table 3: Analysis of the age of patients.

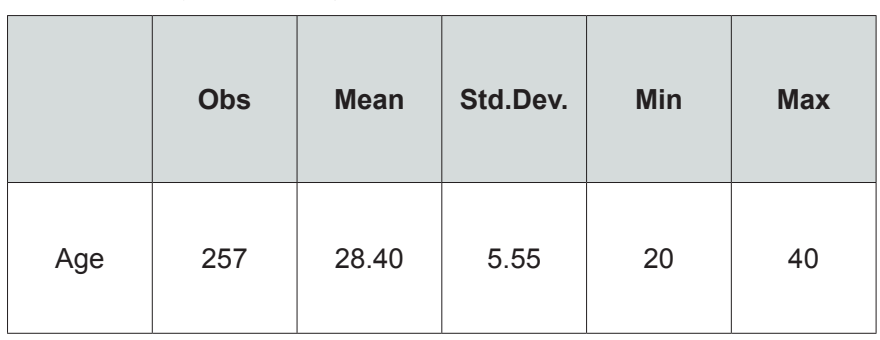

Table 4: Significance of the site in relation to the distal injection.

\begin{tabular}{|c|c|c|c|c|}
\hline Time & Mid & & Ms. & \\
\hline & rrr & P-Value & rrr & P-Value \\
\hline 0 to 30 secs & 13.54 & 0.00 & 0.68 & 0.39 \\
\hline $\begin{array}{c}31 \text { to } 60 \\
\text { secs }\end{array}$ & 10.4 & 0.00 & 1.12 & 0.86 \\
\hline $\begin{array}{c}61 \text { to } 90 \\
\text { secs }\end{array}$ & 3.5 & 0.01 & 0.4 & 0.06 \\
\hline $\begin{array}{c}91 \text { to120 } \\
\text { secs }\end{array}$ & 2.29 & 0.25 & 0.57 & 0.37 \\
\hline
\end{tabular}

Table 5: Significance of the variables.

\begin{tabular}{|c|c|c|}
\hline Variable & \multicolumn{2}{|c|}{ Time } \\
\hline & Sig & Test name \\
\hline Operculum & 0.003 & chi \\
\hline Site & 0 & chi \\
\hline Eight & 0.695 & fisher \\
\hline Gender & 0.737 & chi \\
\hline
\end{tabular}




\section{Discussion}

In Sudan no previous studies were conducted in Oral and Maxillofacial Surgery in relation to the anaesthesia of the long buccal nerve. This clinical trial was done to provide such information, and further more to aid in improving the clinical environment where both the dentist and the patient are relaxed and confident.

This study was conducted at KTDH in patients of age range 20-40 years (mean age of 28.40 years) presented to extract the lower second and third molar during the period from 2008-2011. Two hundred and fifty seven patients were involved in this study. Patients were divided randomly into three groups. The first group received injection of $0.6 \mathrm{ml}$ of $2 \%$ lidocaine distal and buccal to the last molar in the oral cavity to block the long buccal nerve. The second group received the same injection in the buccal vestibule in between the roots of the tooth to be extracted. The third group received the injection mesial to the tooth to be extracted.

Patients distribution according to gender was $33.90 \%$ males and $66.10 \%$ females. Regarding the onset of anaesthesia in relation to the site, the group who received injection of local anaesthesia in between the roots was anaesthetized at 30 seconds is 64.70 $\%$, compared to $19.10 \%$ of the group received block injection, and $16.20 \%$ of the patients received mesial injection. This result tells that the first site gives the fastest onset of anaesthesia with statistical significance ( $\mathrm{p}$-value of 0.00 ). The result may be affected by a number of anatomical factors. Hendy et al found that the nerve trunk branches into smaller branches $3-12 \mathrm{~mm}$ below the deepest concavity of the anterior boarder of the ramus [11]. As has been known that the mantle bundle of nerve fiber (i.e. The most superficial nerve fibers in the fasciculus) is the first fibers to be reached by local anaesthetic solution, therefore the first to be blocked. The mantle fibers supplies the proximal areas. While the distal areas supplied by the core bundle (ie.the deepest nerve fibers in the fasciculus) as mentioned by Malamed [12]. This may explain the fast onset when injecting local anaesthetics closer to the tooth to be extracted.

Blair and Erlanger found that in order to block an impulse in a nerve, it needs at least to block three successive nodes of Ranvier. The longest internodal span had been found in neurons of greater diameter as described by Vizoso and Young. The longest inter nodal span in the Inferior alveolar nerve were measured by Rood and found to be $1.8 \mathrm{~mm}$. Then about $6 \mathrm{~mm}$ is needed to block the nerve impulse [4].

Another explanation described by Mac Gregor who reported an aberrant nerve arising from a small foramin in the retromolar fossa in which the nerve was thought to arise from the Inferior alveolar nerve within the mandible [13]. This idea was also described by Turner and Jablonski [14]. This variation was found to be more common in native American than in other groups like European, Asian, African or Indian descents as reported by Sawyer and kiely [9].
The presence of operculum shows delay in the onset of anaesthesia. The highest percentage of the teeth with operculum was anaesthetized at more than 120 seconds by a percentage of $39.10 \%$. While the rest of teeth showed $13.20 \%, 19.20 \%, 28.90 \%$ and $31.30 \%$ at time interval of $0-30,31-60,61 .-90$ and $91-120$ seconds respectively.The result was significant statistically with p-value of 0.003 . This result may need more investigations.

In this study the gender distribution was about the same at each time field. At 0 - 30 seconds females showed percentage of $61.80 \%$ in comparison with $38.20 \%$ of males. Females showed percentages of $64.00 \%, 63.20 \%, 62.50 \%$ and $70.90 \%$ at $31-60$, 61-90, 91-120 and more than 120 seconds respectively. While the males showed $36.00 \%, 36.80 \%, 37.50 \%$, and $29.10 \%$ at the same time fields. There was no statistical significance.

The patients who need extraction of the lower seven were 55 cases. Of those patients $36.40 \%$ had the lower eight in the oral cavity, and $63.60 \%$ had missed (impacted or extracted) lower eight. Those who had lower eight molar showed delay in the onset of anaesthesia at times 0-30, 31-60 and more than 120 seconds. The percentage was $31.30 \%$ at $0-30$ seconds, $42.90 \%$ at $31-60$ seconds and $30.40 \%$ at more than 120 seconds. Those who hadn't lower eight molar represented $68.80 \%$ at 0 -30seconds, $57.10 \%$ at $31-60$ seconds and $69.60 \%$ at more than 120 seconds. At $91-$ 120 seconds both groups showed equal percentage of $50.00 \%$. While at 61-90 seconds those who had lower eight showed better response by $60.00 \%$ and those who hadn't lower eight showed $40.00 \%$. There was no significant relation between this factor and the time.

A comparison between the teeth used in this study was made, the lower left eight showed the fastest onset by a percentage of $51.50 \%$ when compared with $25.00 \%$ of the lower right eight, $14.70 \%$ of the lower left seven and $8.80 \%$ of the lower right seven at 0 -30 seconds.The rest of the time fields showed variable results. The results showed no significant relation between the tooth and the onset of anaesthesia.

\section{Conclusion}

According to this research it was found that local anaesthetic injection for anaesthesia of the long buccal nerve to extract lower posterior teeth is best given in the buccal vestibule in between the roots of the tooth to be extracted.This may be referred to anatomical factors. The onset of anaesthesia was the fastest at time of 30 second by a percentage of $64.70 \%$ in comparison with $19.10 \%$ for the block injection and $16.20 \%$ for the mesial injection.

The presence of operculum seems to have an effect on the time as shown by the result.It seems to play a role in delaying the onset of local anaesthesia as $13.20 \%$ of patients were anaesthetized at 30 seconds and $39.10 \%$ were anaesthetized at more than 120 second in comparison with patients who do not have operculum $86.80 \%$ were anaesthetized at 30 seconds and $60.90 \%$ were anaesthetized at more than 120 seconds. The other factors studied shows no significant relation with the onset of anaesthesia, These 
factors are : the gender of the patients, the presence or absence of the lower eight in case of extraction of the lower seven and the tooth number.

\section{Recommendations}

As revealed by this study the use of the new point (in between the roots of the tooth to be extracted) is recommended for long buccal nerve anaesthesia to shorten the time of extraction and support the confidence between the dentist and the patient.

Anatomical factors should be considered such as the presence of operculum. Management of such cases should be done by waiting for more time before starting the operation to avoid painful experience.

Further studies in this field are recommended to be done to improve the medical services all over the world.

\section{References}

1. Howe GL, Whitehead FIH (1990) Local anaesthesia in dentistry. Butterworth Scientific ( $3^{\text {rd }}$ edn.).

2. Kohler BR, Castellon L, Laissle G (2008) Gow-Gates technique: a pilot study for extraction procedures with clinical evaluation and review. Anesth Prog 55(1): 2-8.

3. Meechan JG (1999) How to overcome failed local anaesthesia. Br Dent J 186(1): 15-20

4. Rood JP (1977) Some anatomical and physiological causes of failure to achieve mandibular analgesia. Br J Oral Surg 15(1): 75-82.
5. Lew K, Townsen G (2006) Failure to obtain adequate anaesthesia associated with a bifid mandibular canal: a case report. Aust Dent J 51(1): 86-90

6. Juodzbalys G, Wang HL, Sabalys G (2010) Anatomy of Mandibular Vital Structures. Part I: Mandibular Canal and Inferior Alveolar Neurovascular Bundle in relation with Dental Implantology. J Oral Maxillofac Res 1(1): e3.

7. Stein P, Brueckner J, Milliner M (2007) Sensory innervation of mandibular teeth by the nerve to the mylohyoid: implications in local anesthesia. Clin Anat 20(6): 591-595.

8. Niamtu J (2004) Local anesthetic blocks of the head and neck for cosmetic facial surgery. Part IV. Techniques for the lower face. J Cosmet Dermatol 17(11): 714-720.

9. DeSantis JL, Liebow C (1996) Four common mandibular nerve anomalies that lead to local anaesthesia failures. J Am Dent Assoc 127(1): 1081-1086.

10. Kim HJ, Kwak HH, Hu KS, Park HD, Kang HC, et al. (2003) Topographic anatomy of the mandibular nerve branches distributed on the two heads of the lateral pterygoid. Int J Oral Maxillofac Surg 32(4): 408413.

11. Hendy CW, Smith KG, Robinson PP (1996) Surgical anatomy of the buccal nerve. Br J Oral Maxillofac Surg 34(5): 457-460.

12. Malamed SF (1997) Handbook of local anesthesia. In: Louis S, (4 $4^{\text {th }}$ edn) London.

13. MacGregor AJ (1985) The Impacted Lower Wisdom Tooth. Oxford: Oxford University Press, UK, pp. 194-195.

14. Sinnatamby CS, Last RJ (2006) Last's anatomy: regional and applied. In: Edinburgh (Ed.), (11 ${ }^{\text {th }}$ edn), Churchill Livingstone, UK.

\section{Your next submission with Juniper Publishers will reach you the below assets}

- Quality Editorial service

- Swift Peer Review

- Reprints availability

- E-prints Service

- Manuscript Podcast for convenient understanding

- Global attainment for your research

- Manuscript accessibility in different formats

( Pdf, E-pub, Full Text, Audio)

- Unceasing customer service

Track the below URL for one-step submission https://juniperpublishers.com/online-submission.php 